\title{
CONSCIÊNCIA IMAGINANTE E ANALOGON: O LUGAR DO OBJETO ESTÉTICO NA OBRA DE SARTRE
}

CONSCIENCE OF IMAGINATION AND ANALOGON: THE PLACE OF THE AESTHETIC OBJECT IN THE WORK OF SARTRE

Igor Silva Alves*

\begin{abstract}
RESUMO
Busca-se aqui delinear o lugar do objeto estético na obra de Sartre, compreendendo a especificidade da consciência diante desse objeto. Para tanto, acompanham-se as reflexões do autor em sua obra $O$ imaginário, mostrando a separação da consciência realizante da consciência imaginante, e como somente para esta o objeto estético pode se dar como tal.
\end{abstract}

PALAVRAS-CHAVES: Sartre; consciência imaginante; negatividade; analogon.

\begin{abstract}
Search here to outline the place of aesthetic object in the works of Sartre, understanding the specificity of conscience on that object. To do so, follow the author's reflections on his work the imagination, showing the separation of consciousness realizante of conscience of imagination, and how only to this object can be aesthetic as such.
\end{abstract}

KEYWORDS: Sartre; conscience of imagination; negativity; analogon

É certo que não se encontra na obra de Sartre algo como um sistema das artes, ainda que haja um volume considerável de reflexões sobre crítica de arte. Ainda assim, é possível encontrar ao longo de suas obras algumas indicações de um estatuto fenomenológico da obra de arte, quer dizer, uma compreensão do que é o objeto artístico e como a consciência pode apreendê-lo. Nesse texto, procuro mostrar, por meio de uma descrição da consciência imaginante tal como apresentada em $O$ imaginário, obra de 1939, o lugar que a obra de arte ocupa no pensamento de Sartre, compreendendo a partir do papel da negatividade na constituição da imagem, e como a partir daí pode se dar a constituição de um analogon,

\footnotetext{
* Doutorando em Filosofia - Departamento de Filosofia/USP
} 
elemento fundamental para a obra de arte. As considerações são centradas na descrição da consciência imaginante, pois essas descrições são já a construção dos aspectos estruturais da obra de arte constituída como analogon.

A consciência é sempre consciência de algo, e cada modo de posicionar os objetos deve compreender um modo distinto da consciência, isto é, posicionar um objeto é uma certa forma de a consciência se organizar. Mas, trata-se de modos distintos de uma mesma consciência, pois esta apresenta uma unidade indissolúvel. Compreender o objeto artístico tal como descrito por Sartre demanda uma compreensão do modo como a consciência o posiciona, isto é, o que deve ser o objeto artístico para a consciência posicioná-lo como tal e como esta se relaciona com aquele.

As primeiras indicações sobre a obra de arte nos textos de Sartre aparecem em $O$ Imaginário, em que Sartre afirma que a obra de arte se dá por meio de um analogon, noção que remete diretamente à consciência imaginante, pois é somente para esta que o analogon pode se apresentar como tal. Neste sentido, uma compreensão da noção de analogon deve passar por uma compreensão da consciência imaginante. A consciência imaginante não aparece como tal diretamente, mas somente pela reflexão. Isso porque a imagem de algo tem como objeto apenas o próprio objeto, ou seja, na imagem de uma cadeira o único objeto é a própria cadeira. Por isso, somente a reflexão pode oferecer uma descrição do ato de imaginar. Neste ponto, Sartre faz referência direta a Descartes, ao concordar com este que a consciência reflexiva entrega dados absolutamente certos; por isso mesmo, a parte de $O$ Imaginário destinada à descrição por meio da reflexão é intitulada de "O certo". Parece haver aqui uma referência ao procedimento cartesiano para atingir o cogito, o qual leva em Descartes ao núcleo da substância pensante: eu penso que imagino - o objeto pode ser duvidoso, mas o procedimento e a própria reflexão, não.

\footnotetext{
É necessário repetir aqui o que se sabe desde Descartes: uma consciência reflexiva nos entrega dados absolutamente certos; o homem que, num ato de reflexão, toma consciência de ' ter uma imagem' não poderia se enganar. Sem dúvida, encontramse psicólogos que afirmam que não saberíamos, no limite, distinguir uma imagem intensa de uma percepção fraca. De fato, a confusão é impossível: o que se convencionou chamar de 'imagem' dá-se imediatamente à reflexão (SARTRE, 1996, p. 15).
}

A primeira coisa a notar aqui é que a imagem é uma consciência. Deste modo, ela não pode ser tomada como uma coisa que ocupa a consciência, tampouco como uma idéia fraca ou uma percepção enfraquecida. Posto isso, será fundamental a Sartre mostrar uma distinção entre 
percepção, saber e imagem, tanto que as descrições da imagem serão dadas em oposição à percepção. A este ponto, é preciso separar a consciência imaginante da consciência realizante. De fato, há três maneiras de a consciência intencionar os objetos, o perceber, o saber e o imaginar, e é em relação aos dois primeiros que a consciência imaginante será descrita. A percepção é também certo tipo de consciência, por isso não se pode afirmar que o objeto percebido está na percepção. Tanto percebendo quanto imaginando um objeto, este permanece exterior à consciência.

Quando percebo uma cadeira, seria absurdo dizer que a cadeira está em mim. No momento, fecho os olhos e produzo a imagem da cadeira que acabo de perceber. A cadeira, dando-se imediatamente como imagem, não poderia mais do que antes entrar na consciência. Na realidade, quer eu perceba, quer eu imagine a cadeira de palha na qual estou sentado, ela permanece sempre fora de minha consciência (SARTRE, 1996, P. 18-9)

A reflexão mostra que o objeto da percepção e da imagem pode ser o mesmo, mas nos dois casos ele permanece exterior à consciência. A diferença entre percepção e imagem é a maneira como a consciência se relaciona com estes objetos. A imagem é certo tipo de consciência, ou seja, é um tipo de organização sintética que se relaciona diretamente com objetos existentes e cuja essência íntima é precisamente relacionar-se de tal e tal maneira com estes.

A consciência imaginante é, então, uma estrutura da consciência que aparece em certos momentos, mas que é uma estrutura completa. Não se pode tomar a consciência como sendo passível de divisões, assumindo desse modo percepção, imaginação e entendimento como estruturas distintas e que se complementam umas às outras. A consciência é um absoluto, um negativo absoluto, e ao posicionar uma imagem é a consciência toda que se organiza como imaginante, assim como ao perceber ela se organiza toda também como percipiente. Cada uma dessas maneiras de posicionar o objeto é uma estrutura completa. "Vemos agora que lidamos com consciências completas, ou seja, com estruturas complexas que 'têm como intenção' certos objetos" (SARTRE, 1996, p. 20).

Na percepção, ocorre uma observação do objeto. Porém, essa observação dá um lado do objeto por vez, isto é, o objeto aparece como uma série de perfis, de projeções, embora esteja presente à consciência. $\mathrm{O}$ modo como se observa o objeto exclui uma infinidade de pontos de vistas outros, e o objeto é a síntese de todas essas aparições possíveis. Desse modo, o objeto deve ser apreendido, isto é, deve-se ampliar a cada instante o número de perfis, de 
projeções, compreendidos. "A percepção de um objeto é, pois, um fenômeno com uma infinidade de faces. O que isso significa para nós? A necessidade de dar a volta aos objetos, de esperar, como diz Bérgson, que 'o açúcar derreta"' (SARTRE, 1996, p. 21). No saber, quando se pensa no conceito concreto, pensa-se no objeto inteiro ao mesmo tempo, possui-se a idéia inteira de uma só vez. Isso não significa que não se possa completar a idéia num progresso infinito, mas apenas que se pode pensar a essência concreta de uma só vez, num único ato de consciência, e não há nenhuma aprendizagem a fazer. Estabelece-se, desse modo, uma radical diferença entre pensamento e percepção e, por isso mesmo, não se pode reduzir um ao outro, ou seja, não se pode perceber um pensamento nem pensar uma percepção. "Trata-se de fenômenos radicalmente distintos; um, o saber consciente de si mesmo, que se coloca de uma vez no centro do objeto; o outro, unidade sintética de uma multiplicidade de aparências, que faz lentamente seu aprendizado" (SARTRE, 1996, p. 21).

A imagem parece estar mais próxima da percepção, pois o objeto da imagem também se dá por perfis, em projeções. Mas, o objeto como imagem se dá imediatamente pelo que é: enquanto na percepção um saber se forma lentamente, na imagem o saber é imediato. A imagem é um ato sintético que une a elementos mais precisamente representativos um saber concreto, não imaginado. Daí que não se apreende uma imagem, ela é organizada como os objetos que se apreende, mas se dá inteira como aquilo que ela é, desde seu aparecimento. Se na percepção há sempre a revelação de um elemento novo, na imagem sempre se encontra apenas aquilo que nela se colocou. Um objeto na percepção aparece sempre relacionado de infinitos modos, sendo que essa infinidade de relações constitui a essência desse objeto, havendo por isso sempre algo mais a ser descoberto. Ao contrário, na imagem há uma pobreza essencial: os diferentes elementos da imagem não mantêm relações com o resto do mundo, e só mantêm entre si umas duas ou três relações, aquelas que se pode destacar ou que importam ser detidas em algum momento. E não existem outras relações ocultas que esperariam por uma iluminação para serem reveladas. Além disso, os objetos da imagem só existem enquanto neles pensamos, o que contraria radicalmente a tese por alguns defendida de se tratar a imagem de uma percepção renascente. $O$ objeto da percepção excede constantemente a consciência, enquanto o objeto da imagem é apenas a consciência que se tem dele e, por isso, não se pode aprender nada deste último que já não se sabia antes. Constituído e definido pela consciência que se tem dele, ele só existe enquanto nele se pensa. Em outras palavras, “ $O$ objeto da percepção excede constantemente a consciência; o objeto da imagem é apenas a 
consciência que se tem dele; define-se por essa consciência: não se pode aprender nada de uma imagem que já não se sabia antes" (SARTRE, 1996, p. 23).

O objeto na imagem se apresenta como devendo ser apreendido numa multiplicidade de atos sintéticos. Somando-se a isso o fato de os objetos das imagens não serem essências (percebidos) nem leis geradoras (conceitos), tem-se que o objeto da imagem parece ser objeto de observação. Mas, como a imagem nada ensina, ela jamais pode dar a impressão do novo, jamais revela uma face do objeto, o que é característico da percepção. Surge aí o fenômeno característico da imagem, a quase-observação, uma atitude de observação que nada ensina, como se reafirma o próprio Sartre:

\begin{abstract}
A imagem não ensina nada, não dá jamais a impressão do novo, não revela jamais uma face do objeto. Ela oferece-se em bloco. Nenhum risco, nenhuma demora: uma certeza. Minha percepção pode enganar-me, mas não minha imagem. Nossa atitude em relação à imagem pode ser chamada de quase-observação. Estamos colocados na atitude de observação, mas é uma observação que não ensina nada (SARTRE, 1996, p. 23-4).
\end{abstract}

$\mathrm{Na}$ imagem, uma certa consciência se dá um certo objeto. O objeto aqui é correlativo de um ato sintético, que compreende em suas estruturas um saber e uma intenção. Esta intenção está no centro da consciência, é ela que visa o objeto, enquanto o saber, indissoluvelmente ligado à intenção, especifica o objeto. Constituir a consciência de um objeto como imagem é constituí-la como uma consciência imaginante. Assim, o objeto é contemporâneo à consciência que tomo dele, e ele é determinado por essa consciência, ou seja, não compreende nada além daquilo de que tenho consciência. Nesse ato, o elemento representativo e o elemento de saber estão ligados por um ato sintético, por isso o objeto correlativo desse ato constitui-se simultaneamente como objeto concreto por conta da observação (ainda que uma observação de outra ordem) que faço desse objeto, sensível, e como objeto do saber. O objeto assim constituído é presente de fora e de dentro ao mesmo tempo, pois por um lado nós o observamos, por outro, percebemos nele o que ele é. ${ }^{1}$

Não se deve confundir essa posição imaginária do objeto com a consciência irrefletida que acompanha todo posicionamento da consciência. A consciência irrefletida é consciência

\footnotetext{
${ }^{1}$ De acordo com Sarte, “O objeto se torna presente de fora e de dentro ao mesmo tempo. De fora, pois nós o observamos; de dentro, pois é nele que percebemos o que ele é. Eis porque o mundo das imagens é um mundo onde nada acontece. Eu posso ao bel-prazer, fazer evoluir em imagem este ou aquele objeto, girar um cubo, fazer crescer uma planta, correr um cavalo; não se produzirá jamais a menor defasagem entre o objeto e a consciência”. (SARTRE, 1996, p. 24).
} 
de um objeto heterogêneo à consciência e, por isso, exterior a esta: ela sai de si mesma, transcende-se. Mesmo nesse momento permanece uma consciência não-tética de si.

\begin{abstract}
A consciência reflexiva posiciona como seu objeto a consciência refletida, emito juízos sobre a consciência refletida, envergonho-me ou orgulho-me dela, aceito-a ou a recuso, etc. ... toda consciência posicional do objeto é ao mesmo tempo consciência não-posicional de si (SARTRE, 1997, p. 21).
\end{abstract}

Sartre afirma com isso que toda consciência existe como consciência de existir, mas não é posta como objeto do conhecimento no momento em que se conhece qualquer objeto que seja. Segundo Franklin Leopoldo e Silva,

\begin{abstract}
Quando me recordo de ter visto uma paisagem, recordo a paisagem mas posso me lembrar também que eu vi essa paisagem. Como constatou Descartes, cada vez que penso, sou eu que penso - daí a inseparabilidade, julgava Descartes, entre Eu e pensamento ou entre Eu e consciência.Mas é preciso também atentar para o caráter reflexivo do cogito, isto é, para o fato de que se trata de uma consciência 'de segundo grau'. (SILVA, 2004, p. 40).
\end{abstract}

Eis porque existe um cogito pré-reflexivo: a consciência não-reflexiva torna possível a consciência reflexiva, a primeira fornece o cogito pré-reflexivo como condição para a segunda atingir o cogito cartesiano. Essa consciência pré-reflexiva não é uma nova consciência, mas é o único modo de existência possível para uma consciência de alguma coisa, por isso não é anterior nem exterior a esta. Aqui se encontra outro limite do cogito cartesiano. Este atingia a consciência como um objeto entre outros, pois limitava-se ao plano da reflexão. No entanto, esse saber de si, irredutível, deve estar em outro plano, isto é, ele deve ser algo que acompanha toda posição da consciência, não algo conquistado por alguma posição específica. A consciência pré-reflexiva, esse saber não-posicional de si, acompanha todo ato de consciência, por isso a consciência sempre se sabe consciente ao posicionar qualquer objeto, ou seja, a consciência de cadeira como cadeira-percebida é acompanhada de uma consciência (de) ser consciente da cadeira-percebida. Sendo mais preciso, esse saber de si fundamental nem mesmo se põe como um saber, pois o entendimento é outra forma de posicionar os objetos. Nesse plano, o termo "saber" deve designar certo modo que a consciência tem de se vivenciar. $^{2}$ Observa-se que, embora as descrições das diferentes formas de posicionamento da consciência sejam atingidas apenas pela reflexão, já havia no próprio ato de imaginar uma

\footnotetext{
2 "Toda consciência posicional do objeto é ao mesmo tempo consciência não-posicional de si... Esta nova consciência (de) si não deve ser considerada uma nova consciência, mas o único modo de existência possível para uma consciência de alguma coisa". (SARTRE, 1997, pp. 24-5).
} 
distinção vivenciada, pois esse ato já continha uma consciência (de) consciência imaginante, tal como a percepção possui uma consciência (de) consciência percipiente. Tal como afrima o próprio Sartre: “Compreendemos agora porque a consciência primeira de consciência não é posicional: identifica-se com a consciência da qual é consciência” (SARTRE, 1997, p. 25).

A consciência de árvore como imagem coloca a árvore como algo que não é a percepção. $\mathrm{O}$ ato posicional da imagem pode assumir quatro formas: pode-se colocar o objeto como inexistente; ou como ausente; ou como existente em outra parte; ou neutralizar-se, isto é, não colocar o objeto como existente. Ao contrário, a percepção coloca seu objeto sempre como existente, como algo real. Nos atos posicionais da consciência imaginante, principalmente nos três primeiros, a negação possui um caráter fundamental. "Dois desses atos são negações: o quarto corresponde a uma suspensão ou neutralização da tese. $O$ terceiro, que é positivo, supõe uma negação implícita da existência natural e presente do objeto" (SARTRE, 1996, p. 26). É preciso notar também que esses atos posicionais não se acrescentam à imagem constituída, mas são constitutivos da imagem. Desta forma, a estrutura fundamental da imagem é uma negatividade, a qual não ocorre, pelo menos não do mesmo modo, nos outros modos de a consciência posicionar os objetos, posto que a diferença aqui é o papel que a negatividade exerce. Além disso, é somente no plano da quase-observação que se pode notar a posição de ausência ou de inexistência, uma vez que a percepção coloca a existência de seus objetos e o saber coloca a existência de naturezas constituídas por relações, as quais por isso mesmo são indiferentes à existência encarnada.

Os atos posicionais da imagem têm caráter privativo, negativo, pois a imagem dá seu objeto como um nada de ser. A suspensão da crença na percepção, como, por exemplo, no momento em que se duvida do conteúdo da percepção (essa torre que vejo me parece redonda de longe, mas não se mostraria quadrada se eu me aproximar dela?) implica ainda uma posição de existência daquilo sobre o que se suspende a crença, ou seja, é possível duvidar que a forma da torre que vejo seja redonda, é possível duvidar que o que vejo seja uma torre, mas não se pode duvidar que se está percebendo algo que se estende por um certo espaço. Já na imagem, o objeto da consciência imaginante não está aí, e é posto como tal, ele não existe ou não é posto de modo algum.

Existem julgamentos da percepção que implicam um ato posicional neutralizado. Numa palavra, minha dúvida implica necessariamente uma posição da existência... $\mathrm{O}$ objeto intencional da consciência imaginante tem isso de particular: que ele não está aí e é posto como tal, ou que ele não existe e que é colocado como inexistente, ou, ainda, que não é colocado de modo algum. (SARTRE, 1996, p. 27). 
Ao se produzir a consciência imaginante de tal objeto, realiza-se uma síntese intencional que reúne em si uma série de momentos passados. O que a intenção da percepção visa é o objeto em sua corporeidade, que é susceptível a uma certa percepção, que está a uma certa distância e que possui certa posição em relação a quem percebe. Mas a imagem que se tem desse objeto é uma maneira de não tocá-lo, de não vê-lo, de não percebê-lo, de esse objeto não estar a certa distância, por isso o objeto aparece como ausente à intuição. " $A$ crença, na imagem, coloca a intuição, mas não coloca Pierre. A característica de Pierre não é de ser não-intuitivo, como seríamos levados a acreditar, mas de ser 'intuitivo-ausente', um dado ausente à intuição" (SARTRE, 1996, p. 28). Marcada pela ausência, a imagem envolve um nada: por mais viva que seja uma imagem, ela dá seu objeto como não-sendo. Pondo seu objeto como um nada, a consciência imaginante se dá a si mesma como tal, ou seja, com uma espontaneidade que produz e conserva o objeto como imagem, em oposição à percepção, a qual se caracteriza por uma passividade (guardando o sentido relativo em que se pode falar em passividade aqui), posto que o objeto na percepção está aí, e possui um ser que sustenta os fenômenos intencionados na percepção. Sendo assim, a imagem é sustentada pela consciência, e o único ser que sustenta o fenômeno da imagem é o ser da consciência, porém ele o faz com seu nada essencial.

$\mathrm{O}$ ato fundamental constitutivo da imagem é um ato negativo, o qual se revela em dois momentos: primeiramente há um não ser da imagem, posto que ela é uma ausência, e além disso há uma negação dos objetos reais quando se constitui a imagem, de tal forma que o objeto imaginado está fora do alcance da realidade, o real é mantido à distância do objeto imaginado. A imagem assim tomada se apresenta com uma existência irreal, de tal forma que "para que uma consciência possa formar imagens é preciso que tenha a possibilidade de colocar uma tese de irrealidade" (SARTRE, 1996, p. 238). Essa possibilidade de colocar um objeto como um existente irreal é sustentada por aquilo que a consciência tem de mais profundo e característico ontologicamente, a saber, a possibilidade de a consciência negar um dado, de operar uma negação, o que é sustentado pelo fato ontológico de a consciência liberar o nada. Assim, aquilo que caracteriza a posição de uma imagem é também aquilo que ontologicamente caracteriza o ser da consciência. Desse modo, a negação específica que a consciência opera ao posicionar a imagem é sustentada por uma negação em geral, a qual é mesmo a marca ontológica do ser da consciência, do ser Para-si.

$\mathrm{Na}$ origem desse ato negativo, que é a negação, se encontra o processo de nadificação. Sartre considera esse processo por meio de uma análise do papel que a negação possui para a 
consciência, não afirmando a existência da negação apenas no plano lógico. Do ponto de vista do mundo, talvez não se pudesse afirmar a negatividade. Mas do ponto de vista humano, em que se atribui sentido humano ao concreto, pode-se falar em negação, pois o juízo não se formula a partir dele mesmo, mas a partir de um dado objeto que serve de base para esse juízo. Nessa perspectiva a negação permite a constatação de uma ausência, o que se pode notar, por exemplo, através da fragilidade das coisas. ${ }^{3}$ A ausência surge a partir de uma constatação que se dá como base para esse juízo. Nota-se aqui a capacidade humana de ver o que não é, de constatar o que não há, uma visão de algo que falta, o que Sartre chama de intuição da ausência. O exemplo que Sartre dá em $O$ Ser e o Nada e que esclarece o que se propõe é o do encontro com Pedro num Café, a saber, aquele que deseja encontrar Pedro no Café toma o bar, cadeiras, mesas, as pessoas que lá estão, etc. Todos esses elementos compõem uma totalidade, como pano de fundo, ou seja, esta totalidade não é diretamente intencionada pela consciência. Isso ocorre porque a consciência tem como objeto intencionado algo muito determinado: Pedro, logo a intenção da consciência é Pedro, a expectativa de encontrá-lo. Tudo aquilo que não é o objeto da intenção é recuado a um plano para aquém do objeto intencionado, é recuado para um plano de não-ser. A esse processo Sartre chama de nadificação: “Quando entro nesse bar em busca de Pedro, todos os objetos assumem uma organização sintética de fundo sobre a qual Pedro é dado como 'devendo aparecer'. E esta organização do bar em fundo é uma primeira nadificação" (SARTRE, 1997, p. 51). É importante salientar que esse processo pode incluir atenção provisória, isto é, ao se ver alguém que se parece com Pedro, dirige-se a atenção a esta pessoa, mas tão logo se constate que esta pessoa não é Pedro, esse alguém recua para aquele fundo. Mas, ao se constatar que Pedro não está, "vê-se" a ausência de Pedro, e é isso que permite falar que Pedro não está, isto é, a expectativa da presença de Pedro transforma-se na verificação de sua ausência, que se mostra como relação sintética entre Pedro e o Café. "Pedro ausente infesta este bar e é a condição de sua organização nadificadora como fundo" (SARTRE, 1997, p. 51). E por ser uma relação sintética entre Pedro e o Café, Sartre chama essa ausência de fato objetivo.

\footnotetext{
${ }^{3}$ Encontra-se na ordem humana uma fragilidade que consiste em as coisas deixarem de ser tais como são, uma fragilidade que se encontra nos produtos dos seres humanos. Essa fragilidade, a possibilidade de ser destruído, só aparece para o homem, de tal forma que ele pode constatar como ausente algo que antes ele dizia presente em determinado lugar. "Para haver destruição, é necessário primeiramente uma relação entre o homem e o ser, quer dizer, uma transcendência... O ser considerado é isso e, fora disso, nada... Que é a fragilidade senão certa possibilidade de não-ser para um ser em circunstancias determinadas?”. (SARTRE, 1997, p. 49).
} 
Há um movimento ontológico que deve ser compreendido. Sartre afirma que tal consciência trouxe a ausência de Pedro porque ele coloca o nada como origem desse processo, desse movimento ontológico. Deve-se notar nesse movimento que o nada possui uma posterioridade que não é lógica, ou seja, só é possível falar em nada porque se parte do ser. Além disso, não se pode falar em uma espontaneidade do nada, o nada surge por uma conduta humana, o que revela o ser pelo qual o nada vem ao mundo. Nas palavras de Sartre: "O ser pelo qual o nada vem ao mundo é um ser para o qual, em seu ser, está em questão o nada de seu ser: o ser pelo qual o nada vem ao mundo deve ser o seu próprio nada." (SARTRE, 1997, p. 65). Posto nesses termos, “o nada não se reduz a um mero conceito vazio, desprovido de sentido" (BORNHEIM, 2003, p. 44), mas torna-se um elemento fundamental para a ontologia de Sartre. O nada é posterior ao ser porque é através da consciência que o nada vem ao mundo, de forma que a nadificação assume um caráter constitutivo fundamental da consciência, o que permite a Sartre identificar negação e consciência. Embora ocorra tal identificação, Sartre não define a consciência como tal, pois definí-la assim seria incorrer num processo de coisificação da própria consciência, seria transformar o ser Para-si em ser Em-si.

A consciência é o negativo, e não um negativo qualquer, mas um negativo absoluto, o qual é sustentado pelo ser Para-si. É porque o ser que sustenta a consciência introduz a negação, o nada, no mundo que a consciência surge como o negativo. Por isso mesmo, parece haver uma não identificação entre consciência e Para-si, pois enquanto a consciência é o negativo puro, o Para-si apresenta uma relação dialética e ambígua com o ser Em-si. Este ser Para-si surge de uma fissura do ser Em-si, de tal forma que não só o nada é posterior ao ser, como por isso mesmo o Para-si também é posterior ao Em-si, e será sempre uma relação de nadificação com o Em-si que ele mesmo é de certa forma, à maneira de negar esse Em-si que ele é. "[O Para-si] $\boldsymbol{E}$, na medida que existe nele algo de que ele não é fundamento: sua presença no mundo" (SARTRE, 1997, p. 128). Não é outra coisa que se revela na facticidade, pois não basta dizer que o Para-si simplesmente não é. Ele de alguma forma é, mas é como vazio, como indeterminação, como um nada essencial. Ele é como uma nadificação contínua de seu resquício de ser Em-si, o que se revela como um constante desgarramento do ser Para-si de si mesmo.

Mas a possibilidade própria de ser - a que se revela no ato nadificador - é ser fundamento de si como consciência pelo ato sacrificial que o nadifica; o Para-si é o 
Em-si que se perde como Em-si para fundamentar-se como consciência (SARTRE, 1997, p. 131).

Para que o Para-si possa ser uma nadificação interna do ser Em-si, é preciso que esta nadificação não se interrompa nunca, pois a hipótese de um ser Para-si que não fosse tal relação interna em si mesmo com o ser Em-si que, de alguma forma, ele é, apontaria para uma negação que pudesse não ser uma negação determinada. Como negação radical, o Para-si não só é negação radical daquilo que ele não é, como também é negação radical internamente de si mesmo, seja como negação de sua negação - o que ocorre, por exemplo, na reflexão, ou mesmo no ato imaginário, pois se a percepção apresenta um caráter negativo ao posicionar o objeto como aquilo que não é a consciência, o ato imaginário opera uma negação dessa primeira negação ao nadificar a percepção e recuá-la como fundo do objeto imaginado - seja como negação de seu resquício de Em-si. Não se pode tomar este resquício como uma coisificação ou como reintrodução de substancialidade na consciência, pois este Em-si que o Para-si é nada mais é do que um lastro, sendo insuficiente para determinar a consciência. Tomado desse modo, o ser Para-si não só é ausência de determinação pelo ser Em-si como ele se vivencia continuamente como uma recusa de qualquer determinação possível que este pudesse lhe infligir.

Uma vez que o ser da consciência é nadificação de si, o que caracteriza a consciência é o poder de liberar o nada, de forma que se pode dizer, embora pareça paradoxal, que a consciência é constituída pelo nada. A consciência não é compreendida aqui como uma coisa, uma natureza dada, uma substância ou essência, mas é compreendida pelo seu caráter existencial. Carente de essência, a consciência se apresenta como um vazio, e não sendo um ser dado, ela se constitui como possibilidade de ser, possibilidade que é atingida no movimento de transcendência. $O$ processo de nadificação também está presente na transcendência da consciência; sendo assim, o vazio que é a consciência é uma indeterminação vivida, isto é, pelo movimento de transcendência a consciência busca realizar suas possibilidades. Decorre disso que a nadificação não é uma forma de se excluir do mundo, mas é uma forma de estar-no-mundo, é o modo de a consciência vivê-lo. E é exatamente esse poder de liberar o nada que se encontra no núcleo da consciência imaginante como estrutura ativa.

Se o objeto imaginado é posto à distância do real, então à imaginação não cabe reconstituir de modo positivo na consciência a realidade, já que isso cabe à consciência realizante. Mas, pelo processo de nadificação, a consciência imaginante constitui uma forma 
que se dá como analogon do objeto real. No entanto, na constituição da imagem pela consciência imaginante, tem-se uma intenção que implica um certo saber, isto é, ao constituir a imagem, a intenção visa o imaginado de algum modo determinado, a intenção imaginante atravessa uma camada de consciência que se pode chamar camada do saber. Decorre disso que na consciência imaginante saber e intenção distinguem-se apenas por abstração, só se representa por imagem àquilo que já se sabe de algum modo. Esse saber não pode ser considerado como acrescentado à imagem, mas é a estrutura ativa da imagem, de forma que, embora seja possível existir um saber em estado livre que constitua por si só uma consciência, não existe uma imagem independente de um saber que a constitua. E, embora mantida à distância do real, é por essa estrutura ativa do saber que a imagem mantém sua ligação com o real. As classes da imagem envolvem também objetos do mundo exterior, não apenas idealidades, ou imagens mentais. O que une esses objetos é o fato de a consciência visá-los de um mesmo modo, portar-se diante deles do mesmo modo. Por exemplo, os retratos e caricaturas. Nos primeiros, oferecem-se os detalhes do rosto, porém sem vida, enquanto na caricatura, a maneira como se alteram deliberadamente as relações entre as partes do rosto, dá a expressão, a vida, algo que faltava ao retrato.

Tanto imagem mental quanto retrato e caricatura possuem em comum o fato de o objeto visado poder permanecer idêntico, ou seja, trata-se de tornar presente algo que não está lá. Neste caso, tenta-se encontrar no terreno da percepção algo que está para além dela. Para Sartre,

\begin{abstract}
Nos três casos, viso o objeto da mesma maneira: é no terreno da percepção que eu quero fazer aparecer o rosto de Pierre, que quero 'torná-lo' presente. E, como não posso fazer surgir sua percepção diretamente, sirvo-me de uma certa matéria que serve como analogon, como um equivalente da percepção. (SARTRE, 1996 p. 34).
\end{abstract}

Foto e caricatura, enquanto tais, são coisas. Mas estas matérias só adquirem seu sentido por meio de uma intenção que as anime, elas exigem uma intenção que as interprete como imagens. ${ }^{4}$ Longe de ser uma cópia do objeto, o analogon constitui-se perante a consciência como algo que intencionalmente não é o objeto, algo que separa o objeto do seu contexto, que o forma de modo arbitrário, que nega o ser real do objeto. Pelo analogon, a consciência imaginante procura transcender-se, estabelecer relação com um externo, colocando seu

\footnotetext{
${ }^{4}$ Sartre dá ainda outros exemplos nos quais se nota a presença de um analogon, como as imitações feitas por atores, signos, desenhos esquemáticos, entre outros. Importa aqui que todos esses casos possuem a mesma forma: é um material que se presta como analogon de uma imagem mental, sendo que a diferença entre eles é o material de que são constituídos.
} 
conteúdo como existente por meio de certa espessura do real que lhe serve de representante, embora esse real não esteja dado, seja apenas visado, isto é, apareça como inessencial. As apreensões "real" e "irreal" do mundo se complementam: ao negar o real para constituir a imagem, essa imagem aparece sobre o fundo de uma totalidade sintética, que é o próprio mundo. Apreender o mundo como totalidade sintética e distanciar-se dele é o mesmo ato, possível apenas pela negação.

\begin{abstract}
A totalidade do real, na medida em que é apreendida pela consciência como uma totalidade sintética para essa consciência, é o mundo. A condição para que uma consciência possa imaginar é, portanto, dupla: é preciso ao mesmo tempo que possa colocar o mundo em sua totalidade sintética e que possa colocar o objeto imaginado como fora de alcance em relação a esse conjunto sintético, ou seja, colocar o mundo como um nada em relação à imagem. (SARTRE, 1996, p. 239).
\end{abstract}

Estabelece-se, assim, uma dialética entre real e irreal: em princípio essencial, quando se opera a negação o real aparece como inessencial diante do objeto imaginado que passa a aparecer como essencial, e perante a essência do real o objeto imaginário aparece como inessencial.

A partir de tal dialética, Sartre pode definir qual é o tipo existencial da obra de arte. O objeto artístico só se dá à consciência quando esta se constitui como imaginante, logo, a obra de arte possui uma existência irreal. O objeto estético se dá, portanto, por uma negação do real, o qual se dá à percepção. Desse modo, o objeto estético está para além da percepção e separado do mundo por uma distância absoluta, a distância do nada. Assim, o que o artista realiza é um analogon da imagem mental por ele concebida, mas não realiza propriamente essa imagem mental, sendo mais apropriado dizer que o artista opera uma objetivação dessa ideia. Nesse ato, o artista realiza uma materialização de sua imagem mental, a qual apresenta uma indissolúvel unidade, pois se trata de uma totalização intencional de elementos reais que visam figurar um elemento irreal - mas Sartre alerta que materializar deve ser tomado num sentido muito específico: "Materializar não significa aqui realizar, mas ao contrário irrealizar o material pela função que se lhe atribui" (SARTRE, 1992, p. 215). ${ }^{5}$ É porque o artista, ao criar um analogon, organiza-o como substituto de sua imagem mental que há uma totalização de elementos objetivos em vistas de apontar para um irreal que, efetivamente, não está lá, ou, melhor dizendo, está lá como uma ausência que organiza o material apresentado, sendo este o sentido preciso de se irrealizar um material para que ele se dê como obra de arte.

\footnotetext{
5 "Matérialiser ne signifie pas ici réaliser mais au contaire irréaliser le matériau par la fonction qu'on lui assigne". Tradução minha.
} 
Tomada desse modo, não se pode considerar qualquer parte de uma obra como elemento que funcione separado de seu contexto, pois a obra toda é uma totalidade indivisível. Assim, por exemplo, se se considera somente as cores de um quadro, elas não funcionam mais como material artístico, pois a intenção organizadora do pintor dirige-se ao quadro como um todo, sendo essas cores parte dessa organização totalizada. Ademais, o que um quadro possui de real é uma sobreposição de tintas sobre a tela. Porém, o objeto estético está para além desse real que se oferece à percepção, ele se dá quando é negado esse real que se atinge pela percepção, sendo então reconstituído no imaginário. Nesse ato, o que se oferecia à percepção é recuado como fundo, é posto à distância do objeto estético. De tal forma que, uma vez constituído o objeto estético, não há alteração possível no real que o modifique, ou seja, podese iluminar de formas diferentes um quadro, mas de maneira alguma isso alterará o jogo de luzes, a iluminação que lhe deu o pintor.

Uma vez constituída por um analogon, perceber uma obra de arte significa o mesmo que deixar de atingi-la. É preciso ir além da percepção, e esse analogon, que se faz suporte do objeto estético por ser organização intencional de um material para expressar a ideia do artista, apela para a liberdade de quem contempla a obra. A obra de arte é, portanto, um duplo apelo à liberdade. $\mathrm{O}$ autor livremente organiza o material para expressar o que concebeu, e o expectador deve empenhar sua liberdade e negar o que se dá a sua percepção para atingir a obra de arte.

\section{REFERÊNCIAS}

BORNHEIN, G. Sartre. São Paulo: Editora Perspectiva, 3º edição, 2003.

SARTRE, Jean-Paul. L'Acteur". In: Un Thêátre de Situations. Textos reunidos por M. Contat e M. Rybalka. Paris: Gallimard, Folio, Colettion Essais, 1992. (edição revista e ampliada)

SARTRE, Jean-Paul. O Ser e o Nada. Tradução de Paulo Perdigão. Petrópolis: Vozes, 1997.

SARTRE, Jean-Paul. O Imaginário. São Paulo: Ed. Ática, 1996.

SILVA, F. L. Ética e Literatura em Sartre: ensaios introdutórios. São Paulo: Editora Unesp, 2004. 